\title{
Effects of long term loading on storm capacity of vertically loaded anchors
}

\author{
H. A. Taiebat \\ University of Technology Sydney, NSW, Australia \\ C. P. Thorne \& J. P. Carter \\ The University of Sydney, NSW, Australia
}

\begin{abstract}
In this paper attempts have been made to find the effects of sequential loadings on the ultimate uplift capacity of a typical horizontal plate anchor loaded vertically. A series of finite element analyses was performed where the anchor was subjected to different initial loading under undrained conditions followed by consolidation under sustained loading. The anchor was then loaded under undrained conditions up to failure. The anchor is idealised as a circular plate embedded in a homogeneous soil. The soil is represented by the Modified Cam Clay material model with an undrained shear strength varying linearly with depth. No allowance has been made to model break away between the soil and the anchor. The results of the finite element analyses show that if a low value of the initial loading is applied to the anchor under undrained conditions followed by consolidation, the ultimate undrained uplift resistance of the anchor increases. However, for relatively high values of the initial loading the soil fails during the consolidation period.
\end{abstract}

\section{INTRODUCTION}

Both the exploration and exploitation of hydrocarbons are heading more towards deeper waters. Tension leg, taut and semi-taut leg and semisubmersible platforms are among the options that are used increasingly in deep waters. With the greater depths there are greater needs for more robust anchoring systems to transfer predominantly tensile forces to the ocean floor. Vertically loaded anchors (or VLAs) are among the few technologies currently used for this purpose in deep waters.

The last 20 years has seen a great increase in the capacity of drag embedment anchors, mostly due to improvements in design that have allowed a greater penetration in softer seabeds. This higher capacity has in turn allowed the extension of development into areas with much deeper water and more hostile environmental conditions.

Over the last 10 years or so an entirely new breed of drag embedment anchor has been developed. These anchors are configured at installation as drag embedment anchors. They are placed and installed in much the same way as the conventional drag anchors; the anchors can be penetrated to the required depth by drag forces or by direct penetration. However after penetrating to the required depth the new anchors can be reconfigured so that the anchor pulling line forms a right angle to the fluke, thus increasing the available uplift capacity by a factor of about 2. These anchors have different innovative designs to satisfy the needs for load resistance as well as convenient installation procedure. Unlike the conventional drag anchors, the capacity of the new anchors is not dependent on the direction of pull so that even direct vertical loading can be sustained.

Anchors are usually subjected to a permanent tensile loading, which is a fraction of the maximum undrained capacity of the anchor, and is required for the stability of the platform. They are also subjected to temporary fluctuating loadings applied due to storms and surface or deep currents. The permanent load is significantly less than storm loading and is usually applied in a relatively short period of time and then remains approximately constant with time. This will result in dissipation of the initial excess pore pressures and consolidation of the soil around the anchor so that when storm loading is applied it might be expected that the response to loading differs from that for a single first time load.

The initial capacity of such anchors has been studied both theoretically (e.g., Rowe \& Davis 1982, Pyrah et al. 1985, Booker \& Small 1987, Small et al. 1988, Merifield et al. 2003, Thorne et al. 2004) and experimentally, by model scale or full size tests (e.g. Dahlberg \& Strom 1999). Little work has been published on the effects of long term loading on anchors.

In conventional anchors, it is accepted that a minor increase in ultimate undrained capacity can be expected if the anchor is left under a load less than 
its ultimate undrained capacity for a long enough time to allow for dissipation of pore pressures to occur before the anchor is finally taken to failure. This paper explores theoretically whether this effect is present for VLAs and what the implications are for movement of the anchor and its ultimate capacity.

\section{ANALYTICAL MODEL}

The typical anchor examined in this study is idealised as a $2.5 \mathrm{~m}$ diameter circular plate (although real VLAs may have a rather complex shape and often an innovative design) embedded at a depth of $\mathrm{H}=20 \mathrm{~m}$ below the seabed, i.e. relatively deep. The seabed soil is assumed to obey the Modified Cam Clay material model. Elastic-perfectly plastic material models, such as Tresca and Mohr-Coulomb, do not show any stress softening/hardening, and therefore are not suitable to model the softening/hardening that may occur in the soil below/above the anchor as a result of pore pressure changes. The material properties used to define the Modified Cam Clay model were chosen as those of a typical soft seabed soil and are presented in Table 1.

Table 1. Material properties for the Modified Cam-Clay model.

\begin{tabular}{lc}
\hline Property & Value \\
\hline $\mathrm{M}$ & 1.0 \\
Elastic stiffness, $\kappa$ & 0.05 \\
Plastic stiffness modulus, $\lambda$ & 0.30 \\
Poisson's ratio, $v$ & 0.25 \\
Void ratio at unit p' in e-ln p' space, $\mathrm{e}_{\mathrm{cs}}$ & 2.20 \\
Submerged unit weight, $\gamma^{\prime}$ & $6 \mathrm{kN} / \mathrm{m}^{3}$ \\
Coefficient of permeability, $\mathrm{k}$ & $1 \times 10^{-9} \mathrm{~m} / \mathrm{sec}$ \\
\hline
\end{tabular}

For the purposes of the calculation a normally consolidated soil was assumed giving an undrained shear strength gradient of $1.75 \mathrm{kPa} / \mathrm{m}$. For calculation of the initial effective stress state, the coefficient of lateral earth pressure, $\mathrm{K}_{0}$, was assumed to be 1 .

The geometry of the problem under investigation is axi-symmetric. The finite element program AFENA (Carter \& Balaam 1995) has been used for the analyses of the anchor. The finite element mesh

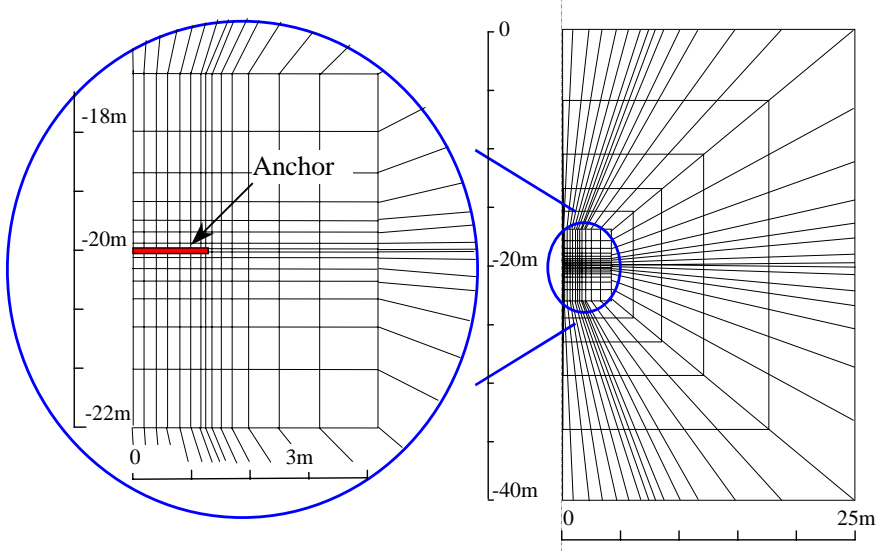

Figure 1. Finite element mesh used in the analyses. used in the analyses consists of 425 isoparametric (8 noded) elements. A thin layer of elements has been used around the anchor in order to capture the effects of local shearing close to the foundation. A schematic representation of the axi-symmetric finite element mesh used in the analysis is shown in Figure 1, which also defines the overall geometry of the finite element model.

The deep anchor plate was assumed to be rigid and impermeable. This latter condition is important because if drainage paths exist through the anchor, dissipation of pore pressures will occur very much faster as water flows from the high pressure areas above the anchor to the low pressure areas below.

\section{FINITE ELEMENT RESULTS}

A series of finite element analyses was performed to investigate the behaviour of the anchor under various types of loading. The results of the analyses are presented in the form of load deflection curves for each type of loading.

\subsection{Undrained and fully drained loading}

The first analyses were to determine the capacity of the anchor loaded under undrained conditions, i.e. very rapid loading, and fully drained conditions, i.e. long term loading. The load deflection curves for both cases are shown in Figure 2. In this figure $\mathrm{P}_{\mathrm{u}}$ represents the undrained ultimate pullout capacity of the anchor, $\mathrm{P}$ is the load level, $\Delta$ is the vertical displacement of the anchor normalized by the anchor diameter, D. The analysis performed under undrained conditions results in a clearly defined ultimate pullout capacity of $\mathrm{P}_{\mathrm{u}}=2540 \mathrm{kN}$ at a vertical displacement of about $0.5 \mathrm{~m}$. However, the drained analysis results in a more abrupt failure at a vertical load of $1440 \mathrm{kN}$, and a vertical displacement of $0.19 \mathrm{~m}$, after which the displacements become unreasonably large. Overall the behaviour under drained loading is softer than that of undrained loading.

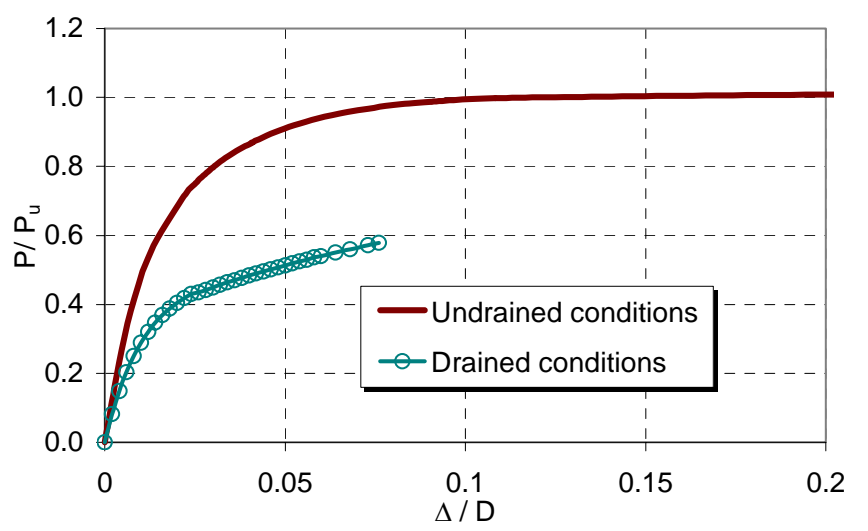

Figure 2. Load-deflection curve of anchor under undrained and fully drained conditions. 


\subsection{Sequential loading}

A series of finite element analyses was performed to show the behaviour when the anchor was initially loaded quickly to a percentage of the undrained pullout capacity, and then this load was maintained at a steady value until the pore pressures were fully dissipated. Following this stage, the anchor was subjected to further loading under undrained conditions, i.e. rapidly, until failure occurred. The finite element analyses show, in general, two different types of response; one when the initial undrained loading is relatively low, and the other when the initial undrained loading is relatively high.

\subsubsection{Sequential loading, low initial loading}

The behaviour of the anchor under initial loads that are below $55 \%$ of the undrained pullout capacity is presented in this section. As a specific example, the behaviour of the anchor under $40 \%$ initial loading is presented in detail.

Under the initial undrained loading, there is an immediate displacement during the loading which is followed by a gradual increase in deflection with time during the consolidation period under the constant load. The rate of displacement decreases and eventually ceases after some time. Figure 3 shows the behaviour of the anchor during the consolidation period under the steadily maintained load of $40 \%$ of the ultimate undrained capacity. The anchor displacement has been plotted against a nondimensional time factor, $\mathrm{T}$, defined here as $\mathrm{T}=\mathrm{kt} / \mathrm{D}$, where $t$ denotes real time. For a "typical" permeability of $\mathrm{k}=1 \times 10^{-9} \mathrm{~m} / \mathrm{sec}$, the time for $90 \%$ consolidation is about 116 days, although $50 \%$ of the consolidation would occur in about 23 days. The rate will depend on the existence or otherwise of soil structure. For example, sand or silt or shell seams in the clay can increase the permeability of the soil mass by several orders. The rate will also be influenced by the amount of disturbance in the soil surrounding the anchor during installation because large scale shearing could disrupt such natural drainage features and decrease the permeability of the soil mass.

Figure 4 shows the load deflection curves for analyses under initial loadings of $20 \%, 40 \%$, and $50 \%$ of the ultimate undrained pullout capacity. The initial loading follows the undrained loading curve, and then, as consolidation under constant loading takes place, the deflection increases to that of the drained loading curve. Subsequent undrained loading results in a relatively stiff response and finally a maximum load is reached that slightly exceeds the first time ultimate undrained capacity.

The structural loading on the anchor is determined by the total pressure distributions above and below the anchor. Figures 5 and 6 show the pressure distribution across a radius of the anchor at the end of the initial loading of $40 \%$ undrained capacity, and at the end of the consolidation under that load, respectively. The pressures have been normalized by the initial vertical effective stress in the soil at anchor level before application of any loading, $\sigma^{\prime}$. It can be seen that while there is only minor variation of effective stresses at the end of undrained loading, the difference between the effective stresses above and below the anchor becomes large and the effective vertical stress below the anchor approaches zero at the end of the consolidation period, which is an indication of possible breakaway and formation of a gap below the edge of the anchor.

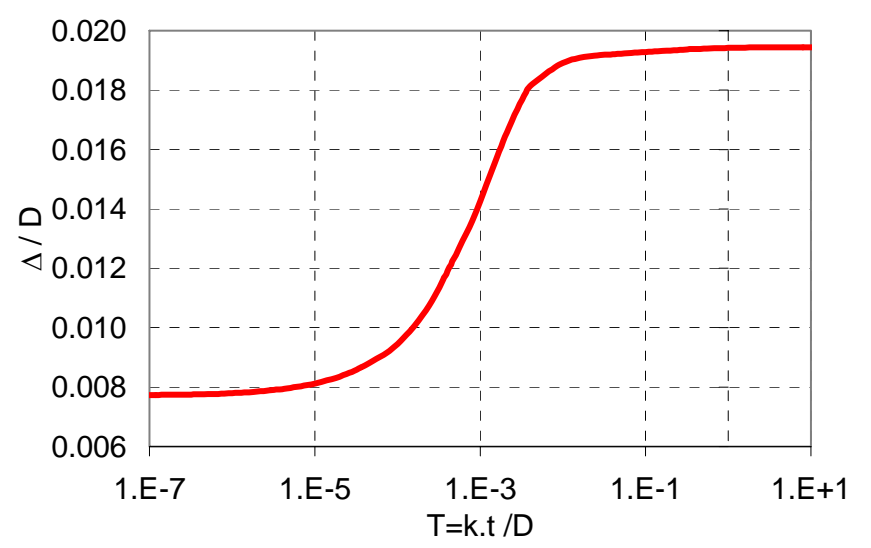

Figure 3. Displacement versus time factor under $40 \%$ of the undrained pullout capacity.

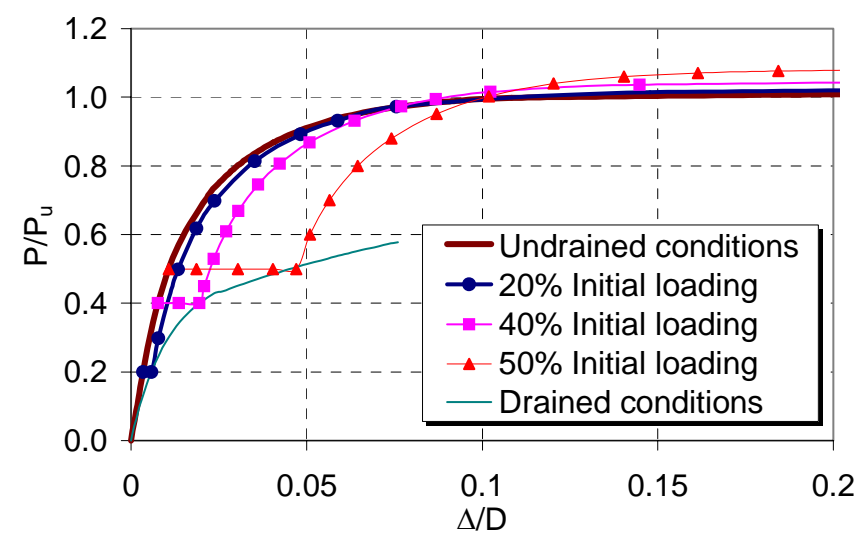

Figure 4. Load deflection curves predicted under low sequential loadings.

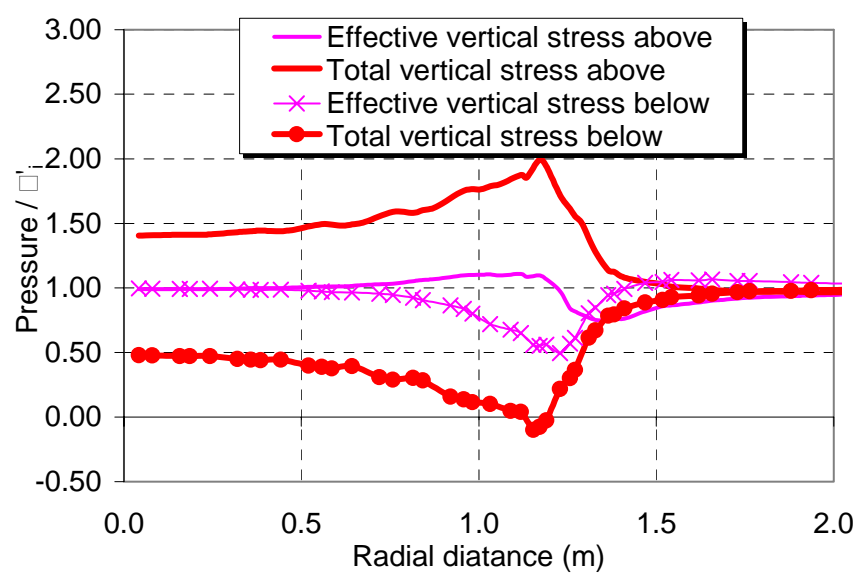

Figure 5. Variation of stresses across a radius of the anchor at $40 \%$ initial loading before consolidation. 


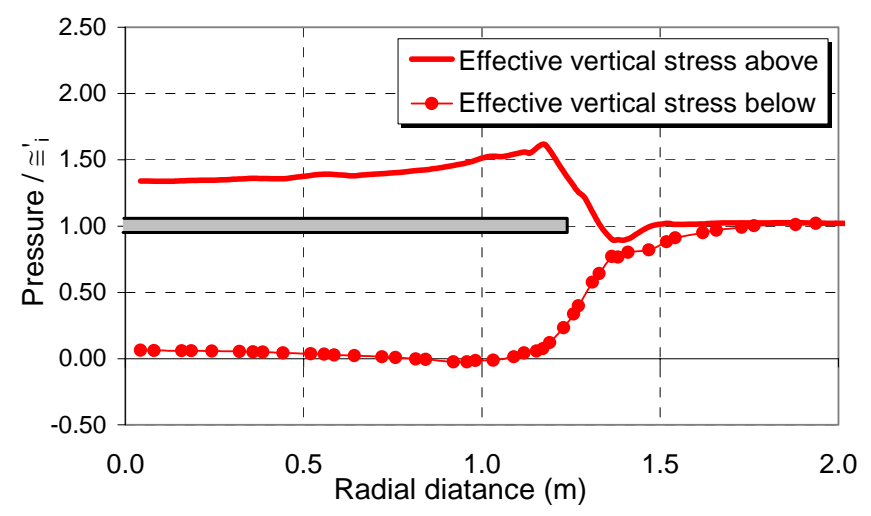

Figure 6. Variation of stresses across a radius of the anchor at $40 \%$ initial loading after consolidation.

As indicated previously, the ultimate pullout capacity of the anchor under staged loading, after consolidation at $40 \%$ of the undrained capacity, is slightly larger than the undrained pullout capacity of the anchor. The results of the analyses do not show any significant difference between the effective stresses predicted at failure below the plate for the two cases of staged loading and first time undrained loading. However, the effective stress predicted at failure above the anchor under staged loading is larger than that predicted under the first time undrained loading. This has the effect of increasing the shearing strength of the soil above the anchor. Figure 7 shows the distribution of the effective stresses at failure above the anchor, across a radius of the anchor for both cases.

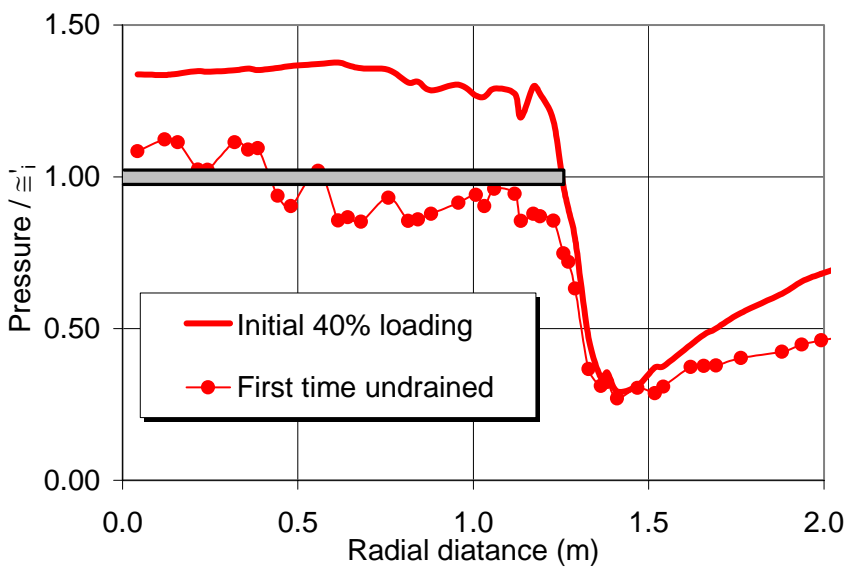

Figure 7. Variation of the effective stresses at failure above the anchor under $40 \%$ staged loading and under the first time undrained loading.

\subsubsection{Sequential loading, high initial loading}

When the anchor was subjected to an initial sustained loading above $55 \%$ of the ultimate undrained capacity, say $60 \%$, the behaviour of the anchor was initially the same as for the loads below 55\%. When consolidation had proceeded to a time defined by $\mathrm{T}=0.036$, i.e. about the time required for $90 \%$ of consolidation, the rate of displacement did not slow down, as occurred at lower initial loads, instead it accelerated before failure (Figure 8). This behaviour is typical for the anchor under initial loading above $55 \%$ of the undrained capacity. To evaluate this behaviour in detailed, the performance of soil around the anchor under $60 \%$ initial loading will be examined here.

Figures 9 to 12 show distributions of the total vertical stress, the minimum principal stress, the shearing resistance and the size of the yield surface, $\mathrm{p}^{\prime}{ }_{\mathrm{c}}$, in the soil around the anchor at a stage before the

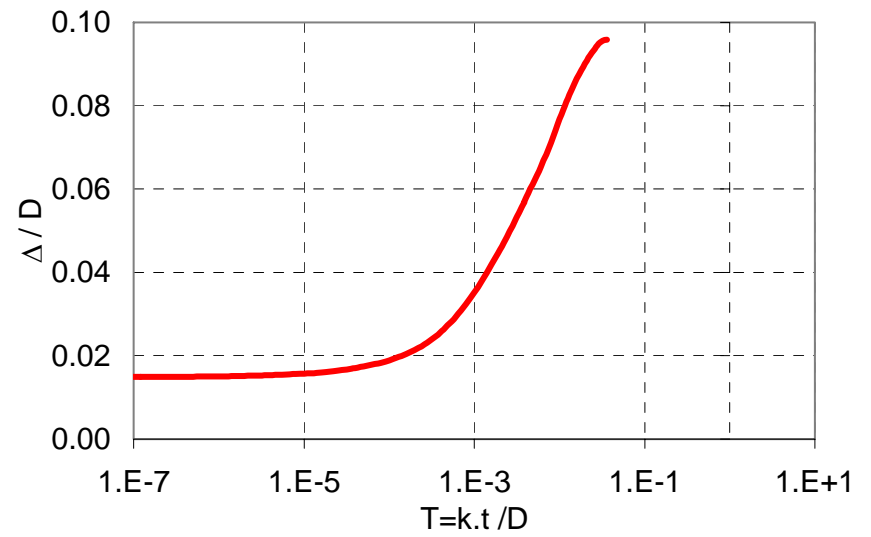

Figure 8. Displacement versus time factor under $60 \%$ of the undrained pullout capacity.

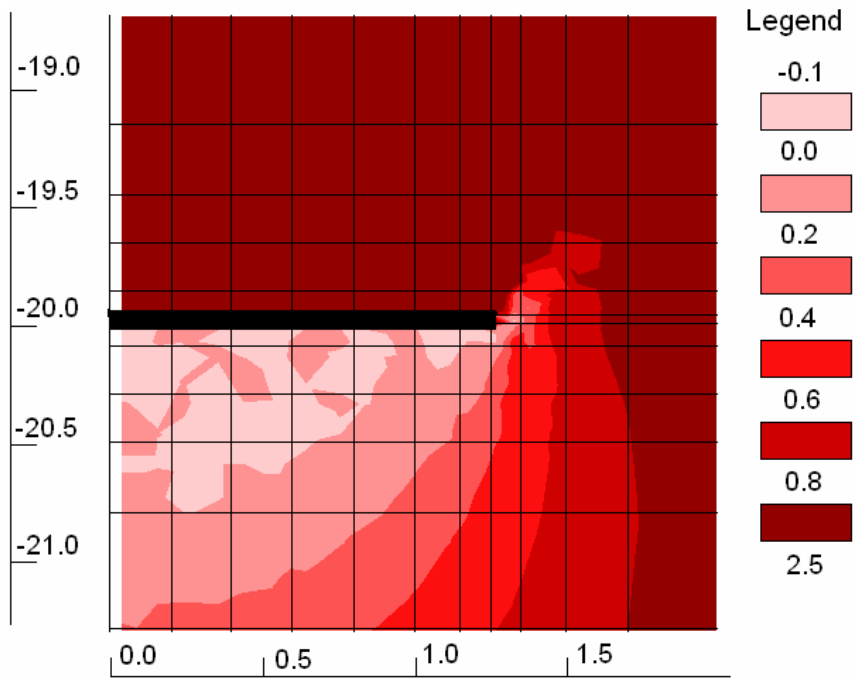

Figure 9. Distribution of the vertical effective stress, normalized by $\sigma_{i}^{\prime}$, in the soil around anchor during consolidation under $60 \%$ initial loading at $\mathrm{T}=0.004$.

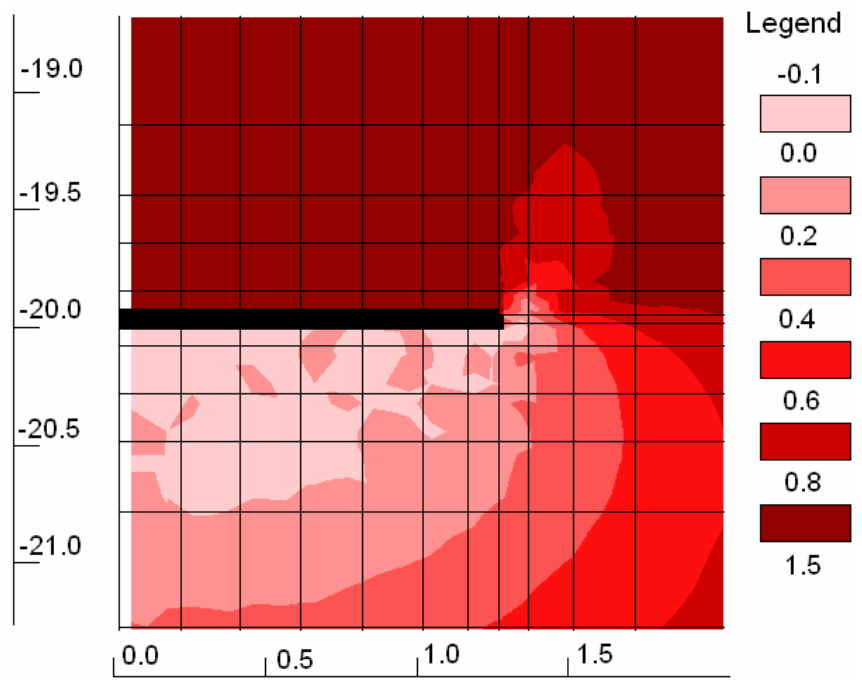

Figure 10. Distribution of the minimum principal stress, normalized by $\sigma_{i}^{\prime}$, in the soil around anchor during consolidation under $60 \%$ initial loading at $\mathrm{T}=0.004$. 
deflection during consolidation accelerated with time. The stresses and the size of the yield surface have been normalized by the initial vertical stress that existed at anchor level. The shearing resistance of the soil around the anchor has also been normalized by the initial shearing resistance of the soil around the anchor. It may be seen that beneath the anchor the vertical effective stress and the minimum principal stress approach zero indicating that the anchor is probably in the process of breaking away from the soil beneath.

Figures 11 and 12 show that a conical zone has formed beneath the anchor where the size of the yield surface, $\mathrm{p}^{\prime}{ }_{\mathrm{c}}$, is negligible and the soil has almost no shearing resistance. The size of the yield surface for the soil just under the anchor is also negligible.

Figure 13 shows the load deflection curves for staged loading for 2 values of the initial loading. The curves for $60 \%$ and $80 \%$ initial loading are terminated

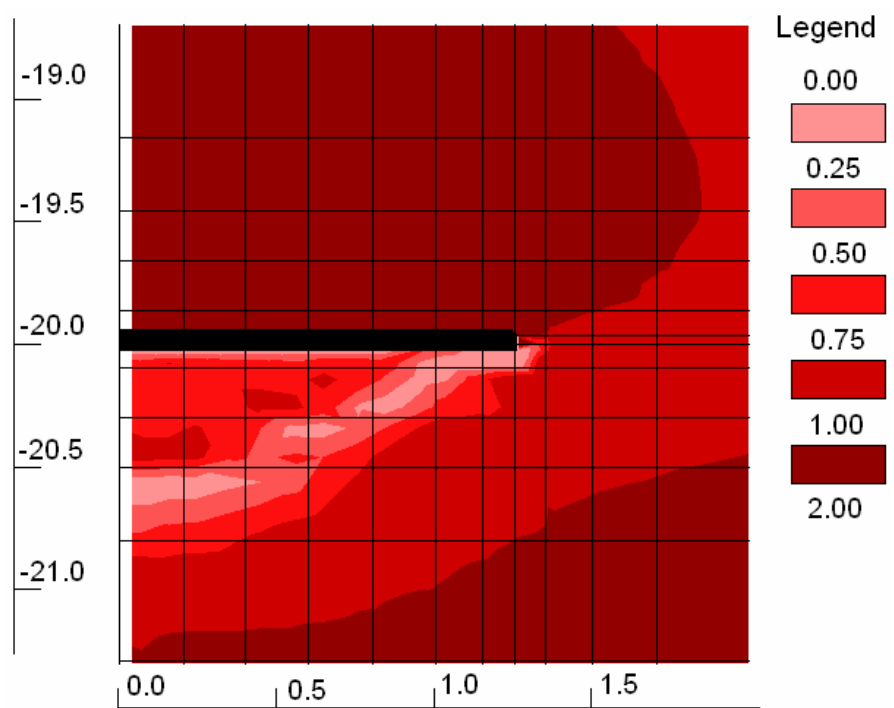

Figure 11. Distribution of the normalized shearing strength $/ \mathrm{s}_{\mathrm{ui}}$ of the soil around anchor during consolidation under $60 \%$ initial loading at $\mathrm{T}=0.004$.

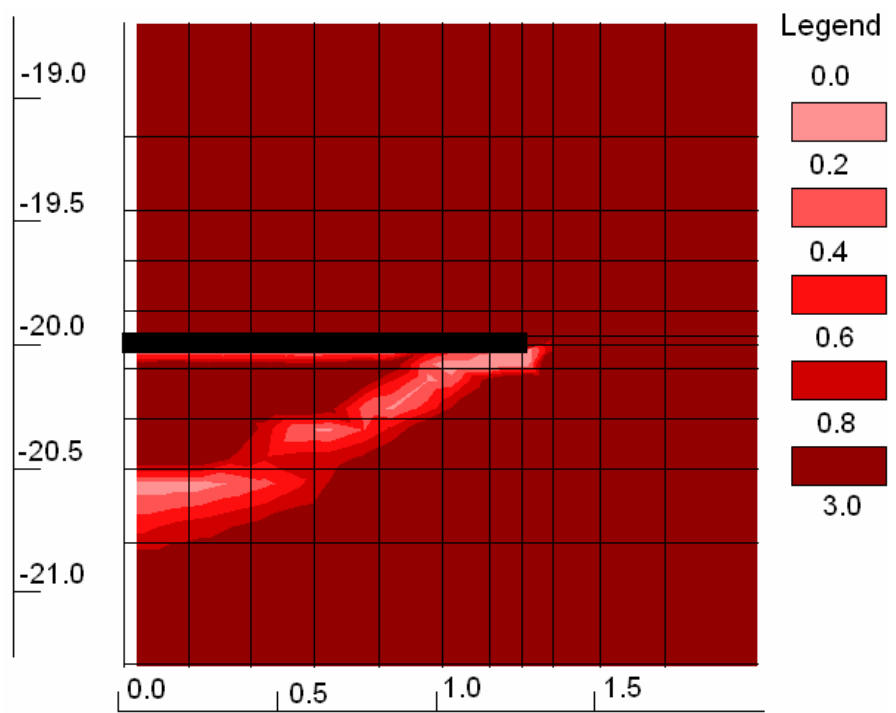

Figure 12. Distribution of the size of the yield surface, $\mathrm{p}^{\prime}{ }_{\mathrm{c}}$, normalized by $\sigma_{i}^{\prime}$, in the soil around anchor during consolidation under $60 \%$ initial loading at $\mathrm{T}=0.004$.

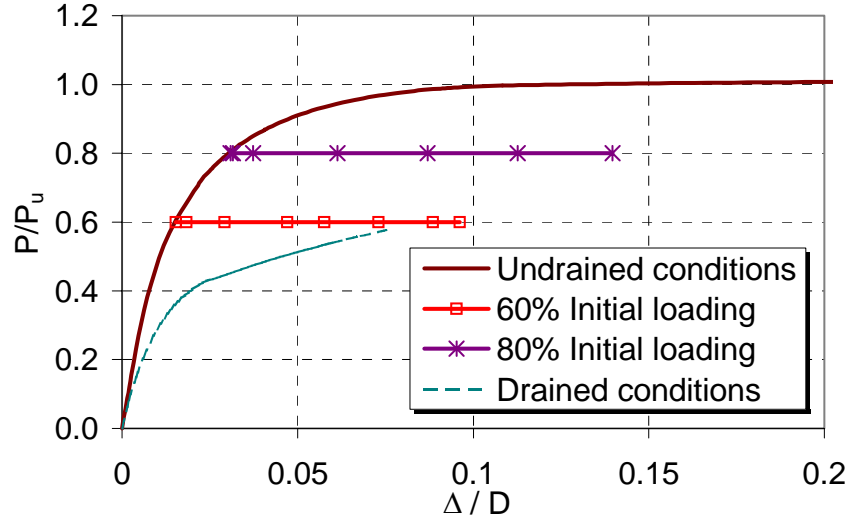

Figure 13. Load deflection curves predicted under high sequential loadings.

before the end of the consolidation period. It is believed that this corresponds to the anchor separating from the soil beneath.

The change in anchor capacity when the anchor separates from the soil beneath has been investigated both theoretically and experimentally. Rowe \& Davis (1982) and Thorne et al. (2004) have shown that, for undrained conditions, separation occurs when the effective overburden pressure on the anchor is less than 6 to 7 times the undrained shear strength of the soil. This criterion appears to be valid for the case considered in this paper. Experimental comparisons have also been made between anchors where dissipation of pore pressures is prevented and where deliberate venting of the soil beneath the anchor has been provided (Baba et al. 1989, Das \& Singh 1994, and Shin et al. 1994). These comparisons show that the ultimate capacity decreases from around 12 to 13 times the undrained shear strength to around 8 to 9 times the shear strength if venting of the underside occurs. Thus dissipation of the negative pore pressures beneath the anchor might be expected to result in a capacity in the order of $60 \%$ to $70 \%$ of that with no dissipation. Based on this observation and the results of the analyses described here it may be concluded that the true long term capacity of an anchor preloaded in the manner assumed is in the range of $50 \%$ to $60 \%$ of the undrained pullout capacity.

\section{CONCLUSIONS}

There are a number of conclusions and recommendations that can be made based on the results of the study presented here.

1) Long term loading of up to $55 \%$ of the undrained pullout capacity increases the ultimate undrained staged loading capacity by up to $20 \%$.

2) Long term loading at loads greater than $55 \%$ of the undrained pullout capacity is likely to result in separation of the anchor from the soil beneath with a large increase in deflection and even failure. 
3) The time for the dissipation of pore pressures and failure to occur for the anchor at a relatively large initial loading depends on the loading level. In a stage loading under an initial loading of $60 \%$ of the ultimate undrained capacity, failure occurred at $\mathrm{T}=0.036$ while under an initial loading of $80 \%$, it occurred at $\mathrm{T}=0.004$.

4) The time for a real anchor to reach these time factors depends on the soil mass permeability. For a $2.5 \mathrm{~m}$ diameter anchor and a fairly typical value of permeability of $\mathrm{k}=10^{-9} \mathrm{~m} / \mathrm{sec}$, the time for $50 \%$ consolidation is about 23 days while for $90 \%$ consolidation it will be 116 days.

5) Soil permeability and uniformity are likely to vary widely from site to site. The rate of consolidation will depend primarily on the existence or otherwise of soil structure. For example, sand or silt or shell seams in the clay can increase the permeability of the soil mass by several orders. The rate will also be influenced by the amount of disturbance in the soil surrounding the anchor during installation because large scale shearing could disrupt such natural drainage features and decrease the permeability of the soil mass. It is disadvantageous to site VLAs in areas of thin sand or silt seams.

6) Based on the data presented in this paper, the fully drained long term capacity of the anchor is estimated to lie between $50 \%$ and $60 \%$ of the undrained pullout capacity. This aspect of the behaviour of anchors deserves more attention than it has received to date. In particular, the long term load capacity needs to be evaluated with more precision both experimentally and theoretically.

7) Because real VLAs have tynes on the leading edge of the fluke it is likely that the dissipation of pore pressures around a real anchor will be rather more rapid than for the circular anchor considered here. If any drainage path exists through the anchor the times for dissipation will decrease significantly.

\section{ACKNOWLEDGEMENT}

The research described in this paper was conducted as part of the work of the Special Research Centre for Offshore Foundation Systems, established and supported under the Australian Research Council's Research Centres Program.

\section{REFERENCES}

Baba, H. U., Gulhati, S. K. \& Datta, M. 1989. Suction effect in plate anchors in soft clays. Proceedings $12^{\text {th }}$ International Conference on Soil Mechanics and Foundation Engineering, Rio de Janeiro, Vol. 1, pp. 409-412.
Booker, J. R. \& Small, J. S. 1987. The time deflection behaviour of a rigid under-reamed anchor in a deep clay layer. International Journal for Numerical and Analytical Methods in Geomechanics, Vol. 11, pp. 269-281.

Carter, J. P. \& Balaam, N. P. 1995. AFENA - Users' Manual. Centre for Geotechnical Research, Department of Civil Engineering, University of Sydney, Australia.

Dahlberg, R. \& Strom, P. J. 1999. Unique onshore tests of deepwater drag-in plate anchors. Ocean Technology Conference. pp 713-723.

Das, B. M. \& Singh, G. 1994. Uplift capacity of plate anchors in clay. Proceedings $4^{\text {th }}$ International Offshore and Polar Engineering Conference, Osaka, Japan, Vol. 1, pp. 436442.

Merifield, R. S., Lyamin, A. V., Sloan, S. W., \& Yu, H. S. 2003. Three dimensional solutions for stability for plate anchors in clay. Journal of Geotechnical and Geoenvironmental Engineering, ASCE, Vol. 29 No. 3, 243-253.

Pyrah, I. C., Hird, C. C. \& Tanaka, Y. 1985. Consolidation behaviour of a single under-ream anchor. Proceedings $5^{\text {th }}$ International Conference on Numerical Methods in Geomechanics, Nagoya, pp. 629-636.

Rowe, R. K. \& Davis, E. H. 1982. The behaviour of anchor plates in clay. Géotechnique, Vol. 32, No. 1, pp. 9-23.

Shin, E. C., Das, R. N., Omar, M. T., Das, B. M. \& Cook, E. E. 1994. Mud suction force in the uplift of plate anchors in clay. Proceedings $5^{\text {th }}$ International Offshore and Polar Engineering Conference, Vol. 1, pp. 462.466.

Small, J. S., Thorne, C. P. \& Ta, L. 1988. Effect of pore pressure dissipation on the behaviour of plate anchors in clay. Proceedings $8^{\text {th }}$ International Polar and Offshore Engineering Conference, Montreal, pp. 497-504.

Thorne, C. P., Wang, C. X., \& Carter, J. P. 2004. Uplift capacity of rapidly loaded strip anchors in uniform strength clay Géotechnique, Vol. 54, No. 8, pp. 507-517. 